\title{
Violência e Segurança Pública: uma síntese da produção da Diest nos ÚLTIMOS DEZ ANOS ${ }^{1,2}$
}

Helder Ferreira ${ }^{3}$

Milena Karla Soares ${ }^{4}$

\section{INTRODUÇÃO}

Violência e segurança pública são temas que estiveram no radar dos estudos do Ipea desde os primeiros anos da criaçáo do instituto, mencionados, entretanto, de forma incidental e esparsa, em análises sobre diferentes temáticas (Silva, 1971; Ipea e Unicef, 1990; Demo e Oliveira, 1995; Sobrinho e Parente, 1995; Barros, Piola e Vianna, 1996; Musumeci, 1998). É na década de 2000, no entanto, que săo desenvolvidos os primeiros estudos em que segurança pública e violência constituíam o objeto principal, fomentando o desenvolvimento autônomo de uma agenda de pesquisa na área (Cerqueira, 2000). Os números crescentes de violência, a importância dada ao tema pela população e a insatisfação com a situação de segurança retratada em pesquisas de opinião são elementos que ajudam a explicar como a segurança pública se torna um dos principais problemas para o governo federal e, por conseguinte, para o Ipea.

Com a criação da Diretoria de Estudos e Políticas do Estado, das Instituiçôes e da Democracia (Diest) em 2009/2010 reuniu-se um grupo de pesquisadores já experiente na área: alguns já se dedicavam a este campo em outras diretorias, trazendo na bagagem trabalhos anteriores; ${ }^{5}$ outros detinham conhecimentos sobre metodologias e técnicas de pesquisa que optaram por aplicar em trabalhos neste campo; e, por fim, os novos contratados do concurso realizado em 2008, que já pesquisavam os campos de segurança pública e justiça.

Além dos estudos desenvolvidos por iniciativa dos próprios pesquisadores, a agenda da diretoria tem sido impulsionada ainda pela realização de parcerias, em especial, com o Ministério da Justiça, com o Conselho Nacional de Justiça (CNJ) e, mais recentemente, com a Secretaria de Governo da Presidência da República, no setor público, e com o Fórum Brasileiro de Segurança Pública (FBSP), organização não governamental $(\mathrm{ONG})$ de reconhecida expertise no tema.

Foi nesse contexto institucional que se firmou e floresceu a agenda sobre violência e segurança pública da Diest. Neste texto, analisamos a produçáo decorrente dos projetos de pesquisa sobre o tema desde a criação da diretoria. $\mathrm{O}$ artigo resulta de um esforço de revisão abrangente dessa produçáo,

1. DOI: http://dx.doi.org/10.38116/bapi29art14

2. Agradecemos a interlocução com Daniel Cerqueira para a definição do objeto do artigo e a Luseni Aquino e demais organizadores da publicação pelas críticas e sugestões às primeiras versões.

3. Técnico de planejamento e pesquisa na Diretoria de Estudos e Políticas do Estado, das Instituições e da Democracia (Diest) do Ipea.

4. Técnica de desenvolvimento da administração na Diest/lpea.

5. Entre 2000 e 2009 (período anterior à Diest), linhas de pesquisa se desenvolveram na Diretoria de Estudos e Políticas Sociais (Disoc), na Diretoria de Estudos e Políticas Macroeconômicas (Dimac) e na Diretoria de Estudos e Políticas Regionais, Urbanas e Ambientais (Dirur). Na Disoc, os trabalhos se concentraram no acompanhamento da política federal de segurança pública, entre 2001 e 2010, especialmente a partir da criação da Coordenação de Direitos Humanos, Justiça e Cidadania, em 2004. Na Dimac, foram realizados estudos econômicos sobre determinantes da criminalidade e efetividade da política de segurança pública (Ipea, 2004), enquanto na Dirur, a tônica foi nos estudos sobre custos da criminalidade (Lima e Dias, 2014). 
orientada pela preocupação em não deixar nenhuma das publicaçôes de fora da análise, de modo a que o texto sirva como uma espécie de inventário para referência futura. Mas, para além de relacionar e descrever, busca-se aqui encontrar a "voz" da diretoria. Nesse sentido, em que pese a diversidade das pesquisas e dos próprios pesquisadores, a pergunta que nos mobilizou foi: o que a Diest tem a dizer sobre violência e segurança pública?

\section{SÍNTESE DAS PUBLICAÇÕES}

Analisando o conjunto de trabalhos produzidos na diretoria nos últimos dez anos, ${ }^{6}$ foi possível identificar e sintetizar os principais achados e recomendaçóes dos pesquisadores em alguns temas centrais, os quais foram organizados nesta seção em duas subseções: na primeira, os estudos que visam compreender o fenômeno violência; na segunda, os estudos que versam sobre políticas de segurança pública.

\subsection{Violência}

É larga a produção que busca descrever e compreender a violência como fenômeno social. Sintetizamos os achados desses trabalhos nos itens a seguir, que transmitem seis mensagens principais.

\section{Mais da metade da população brasileira tem muito medo da violência}

Levando em conta a percepção social, o medo da violência está disseminado no Brasil. Pesquisa sobre sensação de segurança realizada em 2012, no âmbito do descontinuado projeto Sistema de Indicadores de Percepção Social (SIPS), revelou que 62,5\% das pessoas tinham muito medo de ser vítima de assassinato. Porcentagens igualmente altas registradas para outras violências foram: assalto à mão armada (62,3\%), arrombamento de residência (61,6\%) e agressão física $(54,5 \%)$ (Oliveira Júnior e Alencar, 2012). O medo é menor nas regióes Sul e Sudeste, o que pode estar correlacionado com níveis mais baixos de violência nessas regióes ao menos no que se refere aos dados de homicídios (Cerqueira et al., 2020a).

\section{Os homicídios são territorial e situacionalmente concentrados}

Uma série de análises realizadas na Diest mostram que, qualquer que seja a escala, a ocorrência de homicídios segue certa concentração territorial. Ao olhar para uma cidade, por exemplo, verificamos que os homicídios se concentram em bairros com piores indicadores educacionais (Cerqueira et al., 2016b). Ao comparar os municípios entre si, observamos diferentes dinâmicas: entre os rurais, as maiores taxas de homicídios estão naqueles marcados por conflitos fundiários (com presença de territórios indígenas, assentamentos da reforma agrária e os localizados na Amazônia Legal) e com maior vulnerabilidade econômica e social infantojuvenil (Cerqueira et al., 2020b); entre os grandes municípios (com mais de 100 mil habitantes), os mais violentos são também aqueles com piores

6. Para elaborar esta seção foi realizado um levantamento no repositório institucional das publicações na área de segurança pública da Diest a partir de 2009. Isto resultou em uma primeira lista de mais de cem trabalhos, dos quais foram excluídos aqueles relativos às políticas de drogas e de justiça, já abordados em outros artigos desta edição. Ao final, a análise se concentrou nos seguintes itens: quatorze textos para discussão, doze capítulos de livros, nove artigos do periódico Boletim de Análise Político-Institucional, sete relatórios de pesquisa (na maioria realizados em cooperação com parceiros), oito relatórios institucionais (as publicações do Atlas da Violência, desenvolvido e mantido em parceria com o FBSP, disponível em: <https://www.ipea.gov.br/atlasviolencia/quem/3/sobre>), seis notas técnicas e três livros. Ressalte-se nesse conjunto a publicação de número especial do Boletim de Análise Político-Institucional (número 11) com foco em proposições para a política nacional de segurança pública e a atuação da Secretaria Nacional de Segurança Pública. Apenas as publicações de autoria de técnicos do Ipea foram consideradas na análise. 
resultados em indicadores de desenvolvimento humano, sendo que, em 2017, as taxas variavam de 2,7 a 145,7 homicídios por 100 mil habitantes (Cerqueira et al., 2018a; 2019b).

Comparando-se as regióes brasileiras, os homicídios atualmente concentram-se no Centro-Oeste, Norte e Nordeste. Entre 2005 e 2008, com quedas subsequentes, o Sudeste inverteu sua posição de região com maior taxa de homicídios para a de menor taxa. Em relação aos estados, enquanto as taxas de Espírito Santo e São Paulo caíram quase 50\% entre 2008 e 2018, as taxas de Acre, Ceará, Rio Grande do Norte e Roraima cresceram mais de 100\% (Cerqueira et al., 2020a).

Por fim, em termos mundiais, há uma concentração dos homicídios na América Latina e no Brasil, com taxas crescentes desde 1980, raros anos de queda e crescimento ininterrupto desde 2007 (Cerqueira et al., 2013; 2016a; 2017; 2018b; 2019a). É fato que, em 2018, observou-se uma expressiva queda na taxa de homicídios brasileira, um fenômeno em si auspicioso, mas que ainda não foi inteiramente compreendido (Cerqueira et al., 2020a).

Adicionalmente, além da concentração espacial, é possível utilizar preditivos situacionais como insumos para formulação de políticas de prevenção: os homicídios são em sua maioria praticados com o uso de armas de fogo, concentram-se nas ruas/estradas, nas estaçóes primavera e verão, nos finais de semana e no período noturno (Cerqueira et al., 2019; 2020a).

\section{Homens jovens, negros e de baixa escolaridade são as maiores vítimas dos homicídios}

A sobremortalidade juvenil por homicídios tem sido apontada em vários estudos (Cerqueira et al., 2016a; 2017; 2018b; 2019a; 2020a). Estima-se em 1,5\% do produto interno bruto (PIB) brasileiro o custo anual da juventude perdida em virtude de mortes violentas (Cerqueira e Moura, 2014a). O desemprego e a baixa taxa de atendimento escolar de adolescentes e jovens parecem estar na raiz desse fenômeno (Cerqueira e Moura, 2014b; Cerqueira e Moura, 2019).

De igual modo, a sobrevitimização de pessoas negras foi analisada por diferentes estudos (Oliveira Júnior e Lima, 2012; Cerqueira e Moura, 2013; Cerqueira et al., 2016a; 2017; 2018b; 2019a; 2020a). Análises econométricas levaram à conclusão de que diferenças socioeconômicas e demográficas não são suficientes para explicar a sobrevitimização dos negros, restando o racismo como fator explicativo (Cerqueira e Moura, 2013). Controlando as variáveis escolaridade, local de residência, idade e estado civil, estima-se que, no Rio de Janeiro, por exemplo, um indivíduo negro tenha 23,5\% mais chances de sofrer homicídio que um não negro (Cerqueira e Coelho, 2017).

\section{A vitimização de mulheres e de pessoas LGBTQI+ está ligada ao gênero}

As raízes da violência de gênero são estruturais. Em sociedades patriarcais, mulheres são mais vulneráveis a serem vítimas de certos tipos de crimes pelo simples fato de serem mulheres. As dinâmicas sociais que levam ao crime de violência doméstica, de estupro e de feminicídio no Brasil estão, em muitos casos, correlacionadas.

As mulheres são a imensa maioria das vítimas da violência doméstica. $\mathrm{O}$ fato de ser mulher triplica a probabilidade de sofrer violência por parente, conhecido ou cônjuge (Cerqueira, Moura e Pasinato, 2019). Em 2018, a cada dia, em suas residências, foram assassinadas quatro mulheres, em média; indicador que pode ser considerado uma proxy do real número de feminicídios no Brasil (Cerqueira et al., 2020a). 
Na literatura, a participação da mulher no mercado de trabalho é apontada como um dos fatores explicativos desse tipo de violência. Sobre isso, Cerqueira, Moura e Pasinato (2019) encontraram teses e resultados divergentes. Enquanto estudos da economia da família indicariam que o empoderamento econômico feminino, inclusive pela possibilidade de separação, reduziria a violência doméstica contra a mulher, estudos feministas e de gênero revelariam que a participação feminina no mercado de trabalho tem o potencial, em um sistema de dominação masculina, de gerar conflitos e eventualmente o uso da violência. $\mathrm{O}$ resultado do trabalho dialoga com as duas teses, visto que se, por um lado, a participação da mulher no mercado de trabalho estava associada a menor vitimização ante o cônjuge, de outro, tendia a aumentar as chances de sofrer violência por parte do ex-cônjuge.

Além disso, as mulheres representam a maior parte das vítimas de estupro. Parcela significativa dessas são, na verdade, meninas: dois terços dos estupros notificados ao sistema de saúde são contra crianças e adolescentes. Ademais, os agressores são, principalmente, pessoas que convivem com as vítimas: amigos, conhecidos e familiares (Cerqueira e Coelho, 2014; Cerqueira, Coelho e Ferreira, 2017; Cerqueira et al., 2018b).

De modo semelhante, pessoas LGBTQI+ são frequentemente vítimas de violência motivada por ódio e preconceito quanto à sua identidade de gênero. Em que pese a escassez de indicadores de violência contra esse grupo de pessoas, o Disque 100 do Ministério da Mulher, da Família e dos Direitos Humanos registrou 1.685 denúncias desse tipo de violência, incluindo 138 homicídios, em 2018 (Cerqueira et al., 2019a; 2020a).

\section{Os confrontos e tréguas entre facções prisionais afetam os níveis de violência}

Facçóes prisionais e crime organizado têm despontado como tema relevante para a compreensão do fenômeno da violência. As organizaçóes criminosas podem ser vistas como empresas que atuam motivadas por razóes econômicas (Melo, 2015). Nesse sentido, as facções agem de forma estratégica para afirmar seu poder e controle sobre rotas estratégicas dos mercados ilegais, em um cálculo de custo-benefício que pode, ou não, levar as partes concorrentes ao confronto. As variaçóes recentes nas taxas de homicídios de estados do Norte e Nordeste podem ser, em parte, atribuídas à expansão territorial e aos momentos de confronto e trégua entre as duas principais facçóes do país - Primeiro Comando da Capital (PCC) e Comando Vermelho (CV) - e seus parceiros regionais (Cerqueira et al., 2019a; 2020a). O equilíbrio nessa dinâmica é instável e representa incertezas para o futuro das taxas de homicídio no país (Cerqueira et al., 2020a).

\section{É preciso aprimorar a qualidade dos dados e das análises estatísticas sobre violência}

A maioria dos estudos da Diest tem se baseado em dados objetivos de violência, e, ao fazê-lo, os pesquisadores enfrentam uma série de questóes acerca da precisão dos dados. Nesse sentido, esforços foram dedicados a desenvolver ferramentas econométricas visando conferir maior qualidade e confiabilidade às análises estatísticas. A questão das "mortes violentas indeterminadas" e dos "homicídios ocultos" tem sido abordada permanentemente (Cerqueira et al., 2016a; 2017; 2018b; 2019a; 2020a; Cerqueira, 2013). Cerqueira et al. (2016c) propuseram um aperfeiçoamento na utilização da proporção de suicídios por arma de fogo como proxy da prevalência de arma de fogo, considerando as características socioeconômicas das vítimas. Por fim, Cerqueira et al. (2019c) discutem 
aspectos metodológicos para utilização da base de dados do Sistema de Informaçóes Hospitalares para a produção de indicadores sobre violência.

\subsection{Políticas de segurança pública}

Entre os estudos que versam sobre as respostas do Estado ao fenômeno da violência, abordam-se desde programas e políticas de segurança pública até organizações e instituições que compóem o campo. Os achados e as recomendaçóes desses estudos podem ser sintetizados nas mensagens destacadas a seguir.

\section{O aprimoramento da política de segurança pública passa por uma melhor coordenação federativa}

Histórica e constitucionalmente, as políticas de segurança pública estão concentradas nos estados. Nas últimas décadas, tem havido um incremento da atuação do governo federal e dos municípios na segurança pública (Ferreira e Marcial, 2015; Oliveira Júnior e Silva Filho, 2010a). No que se refere à atuação do governo federal, as avaliaçóes dos planos e programas nacionais indicam que tais instrumentos obtiveram implementação e resultados aquém das aspirações apresentadas inicialmente (Silva e Deboni, 2012; Silva, 2017).

A efetiva execução de uma política federativa de segurança pública pode passar por:

- redefinição da divisão de competências e recursos. Por exemplo, a União poderia ter um papel de indução, capacitação e financiamento das políticas dos entes subnacionais (Cerqueira, 2017), tendo em vista a lacuna de capacidades de estados e municípios para a gestáo da segurança pública (Oliveira Júnior e Silva Filho, 2010a; Cerqueira, 2017; Ferreira e Marcial, 2015). Outro exemplo envolve as guardas municipais, que têm replicado o modelo coercitivo da polícia militar, em lugar de adotar um modelo de atuação preventiva, com foco em açôes locais sociais (Cerqueira, 2017; Oliveira Júnior e Silva Filho, 2010a; Ferreira e Marcial, 2015);

- aumento da capacidade institucional do governo federal, começando por rever a insuficiente estrutura da Secretaria Nacional de Segurança Pública (Senasp), responsável pela coordenação do plano nacional (Cerqueira, 2017), e aprimorar os sistemas de informação, que atualmente não estão qualificados para direcionamento, monitoramento e avaliação das ações (Oliveira Júnior e Silva Filho, 2010a; Cerqueira, 2017); e

- fortalecimento do financiamento federal, que apresenta forte flutuação no montante de recursos e é implementado via convênios demasiadamente burocráticos (Cerqueira, 2017), começando pela adoção de outros instrumentos, a exemplo das transferências fundo a fundo e dos termos de compromisso (Ferreira e Marcial, 2015). ${ }^{7}$

\section{É preciso transformar as polícias}

Um dos indícios que apontam a necessidade de reforma das políticas é a falta de confiança da população nas instituições policiais. Baseado em survey com a população, Oliveira Júnior (2011) indicou que a confiança nas instituiçóes policiais depende das percepçóes sobre sua eficiência e adequação às funções para as quais são idealizadas. O estudo também mostrou que pessoas jovens e mais escolarizadas tinham uma visão pior do desempenho das polícias, e os não brancos demonstraram

7. Inclusive, novos fundos poderiam ser criados: Cerqueira, Lima e Bragança (2015) analisaram a experiência de um modelo privado de financiamento de programas de prevenção ao crime baseados em títulos privados, e considerando inexequível vincular o orçamento da segurança pública a receitas tributárias, propuseram a criação de um novo fundo para segurança pública. 
menos satisfação com o atendimento que lhes foi prestado por policiais. Oliveira Júnior e Alencar (2012) indicaram, em 2012, que $21,4 \%$ e 20,6\% da população não confiava na polícia militar e na polícia civil, respectivamente.

A falta de confiança na polícia pode ter relação com fatores como a violência policial, que é insuficientemente registrada e processada (Cerqueira et al., 2016a; 2017; 2018b), a falta de controle externo das polícias (Cerqueira, 2017; Cerqueira et al., 2017; Ferreira e Marcial, 2015) e o racismo institucional na atuação policial (Oliveira Júnior e Lima, 2012; 2013). Mudar esse cenário não é tarefa fácil, uma vez que esbarra na inércia da cultura organizacional. Tentativas de mudanças "por dentro” têm se mostrado incapazes de superar estes problemas: Oliveira Júnior e Silva Filho (2010b) indicaram, por exemplo, a incapacidade da educação policial de transformar as culturas institucionais e a rotina diária da atuação policial.

Assim, são recomendadas reformas institucionais, como a desconstitucionalização das polícias, permitindo que os estados possam reorganizá-las (Cerqueira, 2017). Tais reformas se deparam com uma série de desafios (Oliveira Júnior e Silva Filho, 2010b), para os quais faltam acordos políticos entre os diferentes atores (Ferreira e Marcial, 2015), o que pode ajudar a explicar por que esse tipo de reforma tem sido deixado de lado (Silva, 2013).

\section{Devemos adotar políticas de segurança pública que funcionem}

As políticas nacionais e internacionais que foram bem-sucedidas na redução da taxa de homicídios têm alguns pontos em comum:

- articulação e pactuação política entre governo e atores sociais;

- açôes preventivas focalizadas em crianças e adolescentes;

- $\quad$ repressão qualificada com uso intensivo de informação e inteligência policial; ${ }^{8}$

- integração das agências estatais por meio de mecanismos de gestáo e com foco em objetivos comuns e metas;

- comprometimento do político principal;

- gestão da segurança pública baseada em evidências científicas;

- controle e retirada das armas de fogo e munição de circulação;

- disseminação de espaços de mediação de conflitos; e

- $\quad$ saneamento do sistema de execução penal ${ }^{9}$ (Cerqueira, 2017; Cerqueira et al., 2018a).

Entre os pontos listados, destaca-se, em especial, a importância das políticas de controle de armas (Oliveira Júnior e Silva Filho, 2010a; Ferreira e Marcial, 2015) e efetividade do Estatuto do Desarmamento para a redução dos homicídios (Cerqueira e Coelho, 2013). Mudanças rumo

8. Também apontado por Oliveira Júnior (2012).

9. No Espírito Santo, Cerqueira et al. (2020c) encontram bons resultados do Programa Estado Presente em Defesa da Vida e do saneamento do sistema prisional na contenção dos homicídios. 
à fragilização dos instrumentos de controle, tal qual observado em $2019,{ }^{10}$ devem ser vistas com preocupação, visto que podem levar ao aumento do número de armas em circulaçáo, e, por conseguinte, intensificar o problema da violência letal (Cerqueira et al., 2020a).

Adicionalmente, no que tange às ações preventivas focalizadas em crianças e adolescentes, as evidências apontam que a educação tem um papel relevante (Cerqueira e Moura, 2014b; Cerqueira e Coelho, 2015; Cerqueira et al., 2016b; Cerqueira, 2016).

Em contraposição, algumas políticas são inefetivas. Cerqueira e Coelho (2015) argumentaram que a redução da imputabilidade penal não é efetiva para controle e prevenção ao crime. Rodrigues e Amstrong (2019) indicaram que a intervenção federal no Rio de Janeiro não surtiu o efeito desejado, uma vez que houve aumento dos homicídios decorrentes da ação policial no estado em 2018, manutenção da política de confronto e a insuficiente queda nos principais indicadores de violência e crime.

\section{A participação social na segurança pública é incipiente e declinante}

O Brasil teve um pico de participação social na segurança pública uma década atrás, com a reforma do Conselho Nacional de Segurança Pública, que se abriu para maior participação da sociedade civil, e a realização da primeira Conferência Nacional de Segurança Pública (Oliveira Júnior e Silva Filho, 2010a; Silva, 2010; Silva e Deboni, 2012); entretanto, a recente reforma do Conselho suprimiu a representação da sociedade civil.

Em nível local, a participação social no policiamento comunitário enfrenta desafios. Em estudo nacional realizado em 2014, verificou-se que os assentos nos conselhos comunitários de segurança eram, de certa forma, controlados pelas próprias corporaçóes policiais, impedindo uma participação social verdadeiramente plural (Oliveira Júnior et al., 2015). Adicionalmente, um estudo realizado no Rio de Janeiro demonstrou que a política de pacificação das favelas esbarra na relaçáo historicamente conflituosa entre polícia e comunidade, intensificada pela ausência de uma instituiçáo mediadora ou de controle da atividade policial, bem como pela ausência de transversalidade e integraçáo com outras pastas, a exemplo de habitação e outras políticas sociais (Rodrigues e Motta, 2013).

\section{Políticas de enfrentamento à violência contra a mulher avançaram, mas carecem de capilaridade e humanização}

A Lei Maria da Penha é um grande marco no enfrentamento à violência contra a mulher. Cerqueira et al. (2015) indicaram que esta lei desempenha um papel relevante na contenção da violência de gênero; entretanto, há limites em seu alcance e efetividade. $O$ primeiro deles é a falta de capilaridade. Em 2013, enquanto, em geral, nas capitais e regióes metropolitanas já eram oferecidos todos os serviços especializados no atendimento à mulher e no enfrentamento à violência doméstica, nas cidades do interior se notavam lacunas de implementação (Martins, Cerqueira e Matos, 2015). Além disso, um segundo desafio é a humanização no acolhimento às mulheres pelo Poder Judiciário, peça-chave no acesso à justiça para as mulheres vitimizadas (Ipea e CNJ, 2019).

10. Cerqueira et al. (2020a, p. 74) relatam: "Em um ano e meio, desde 2019, já foram editados, pelo menos, onze decretos, uma lei e quinze portarias do Exército que trarão como consequência a fragilização dos instrumentos de controle e fiscalização de armas de fogo e munições, 0 aumento do número de armas em circulação no país, a obstacularização do combate ao tráfico ilegal dessas armas e a facilitação de sua obtenção por criminosos, como traficantes e milicianos", e, como resultado, houve quase $200 \%$ de aumento nas vendas de armas controladas pela Polícia Federal no primeiro semestre de 2020, e de 24\% na venda de munições entre janeiro e maio desse mesmo ano (Cerqueira et al., 2020a). 


\section{Há injustiças estruturais no sistema de justiça criminal}

Os estudos sobre o sistema de justiça criminal apontam uma série de problemas, como desigualdade, impunidade e morosidade (Oliveira Júnior e Silva Filho, 2010a), reprodução de desigualdades sociais (Ferreira, Natalino e Santos, 2019) e racismo institucional na atuação policial (Oliveira Júnior e Lima, 2012; 2013).

Com relação à execução da pena, foram destacados os problemas de superlotação e de falta de reintegração social (Oliveira Júnior e Silva Filho, 2010a; Andrade et al., 2015). Uma pesquisa com base em autos processuais (Ipea, 2015b) calculou uma taxa de reincidência criminal legal ${ }^{11}$ de $24,4 \%$ e identificou, entre outros gargalos, a precariedade na assistência aos presos e egressos (Ipea, 2015a). Por fim, também foram objeto de análise os obstáculos à adoção de penas alternativas (Ipea, 2015b).

Outro problema é o acesso a uma assistência jurídica de qualidade, o que prejudica sobremaneira a efetivação do direito à defesa dos acusados e apenados. Moura et al. (2013) calcularam que, em 2012-2013, 95,5\% das comarcas brasileiras possuíam deficit de defensores públicos e que, em 72\% delas, a população em condiçóes de vulnerabilidade não tinha garantido seu acesso a um defensor público. De modo semelhante, em estudo local, Haber e Coelho (2017) verificaram que no Rio de Janeiro não se atingiu o ideal de um defensor público para cada 10 mil pessoas com renda de até três salários mínimos, sendo que havia mais de 25 mil pessoas por defensor em 2015.

\section{CONSIDERAÇÕES FINAIS}

$\mathrm{Na}$ síntese realizada neste artigo, tentamos responder à pergunta inicial (o que a Diest tem a dizer sobre violência e segurança pública?) por meio da identificação de algumas mensagens-chave, relacionadas à compreensão da violência como fenômeno social e às diversas políticas destinadas a enfrentá-la.

A Diest certamente dará continuidade aos projetos de análise e monitoramento dos indicadores de violência. Possivelmente, poderiam ser agregadas novas categorias de análise que subsidiassem a compreensão da dinâmica da violência contra grupos vulneráveis, frequentemente invisibilizados nas estatísticas oficiais, tais como pessoas com deficiência e povos indígenas, bem como estudos sobre as circunstâncias e motivaçôes dos crimes violentos letais e intencionais.

No que se refere aos estudos acerca das políticas de enfrentamento à violência, é provável que a agenda continue a ser pautada pelas demandas de organizaçôes parceiras. Isso se justifica pela inserção institucional do Ipea como órgão de assessoramento governamental, e, ao mesmo tempo, potencializa o impacto da pesquisa na formulação de políticas públicas.

Por fim, entre as inúmeras possibilidades de temas que a Diest poderia incluir em sua agenda, destacamos a necessidade de estudos que avaliem a política criminal de forma global, levando em consideração os impactos na sociedade. A ausência de um processo de avaliação instituído que considere os impactos da política deve-se, por um lado, aos desafios metodológicos quanto, por exemplo, à disponibilidade de dados, e, por outro, à fragmentação da formulação e execução da política criminal entre diversos atores (Poderes Legislativo, Executivo e Judiciário e Ministério Público).

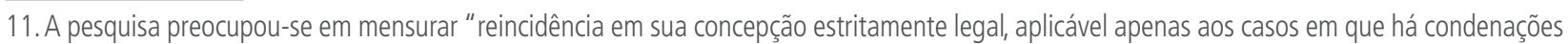
de um indivíduo em diferentes ações penais, ocasionadas por fatos diversos, desde que a diferença entre o cumprimento de uma pena e a determinação de uma nova sentença seja inferior a cinco anos - Código Penal (CP), artigos 63 e 64" (Ipea, 2015a, p. 7). 
Deve-se ter em mente que criminalização, repressão e encarceramento são apenas alguns dos instrumentos de controle sobre as condutas consideradas antissociais, de modo que é preciso uma análise racional, baseada em evidências, que considere políticas alternativas que se prestem aos mesmos fins. Em uma ponta da política, por exemplo, nota-se que as inovaçôes legislativas em matéria penal passam ao largo de discussóes sérias sobre impacto e efetividade. $\mathrm{Na}$ outra ponta, temos observado a escalada do número de pessoas encarceradas, em particular, o encarceramento de jovens negros, a despeito da ausência de evidências sólidas dos custos e benefícios dessa abordagem. Além disso, o sucesso da política não se mede somente em número de pessoas apreendidas, e condenadas, mas na incidência das condutas ora criminalizadas e no respeito aos direitos e garantias fundamentais.

\section{REFERÊNCIAS}

AMAYA, A.; STUCKER, P. Legislaçóes e abordagens institucionais em violência contra as mulheres no sistema de justiça: experiências na América Latina. Brasília: Ipea, 2020. (Texto para Discussão, n. 2552). Disponível em: <http://repositorio.ipea.gov.br/handle/11058/9913>. Acesso em: 11 set. 2020.

ANDRADE, C. et al. O desafio da reintegração social do preso: uma pesquisa em estabelecimentos prisionais. Brasília: Ipea, 2015. (Texto para Discussão, n. 2095). Disponível em: <http://repositorio. ipea.gov.br/handle/11058/4375>. Acesso em: 11 set. 2020.

CERQUEIRA, D. Mapa dos homicídios ocultos no Brasil. Ipea: Brasília, 2013. (Texto para Discussão, n. 1848). Disponível em: <http://repositorio.ipea.gov.br/bitstream/11058/2924/1/ TD_1848.pdf>. Acesso em: 11 set. 2020.

- Trajetórias individuais, criminalidade e o papel da educação. Boletim de Análise Político-Institucional. Brasília: Ipea, n. 9, 2016. Disponível em: <http://repositorio.ipea.gov.br/ handle/11058/7105>. Acesso em: 11 set. 2020.

- Política Nacional de Segurança Pública orientada para a efetividade e o papel da Secretaria Nacional de Segurança Pública. Boletim de Análise Político-Institucional. Brasília: Ipea, n. 11, 2017. Disponível em: <https://www.ipea.gov.br/portal/images/stories/PDFs/boletim_analise_ politico/171005_bapi_11_1.pdf>. Acesso em: 25 ago. 2020.

CERQUEIRA, D.; COELHO, D. Mapa das armas de fogo nas microrregióes brasileiras. In: BOUERI, R.; COSTA, M. Brasil em desenvolvimento 2013: estado, planejamento e políticas públicas. Brasília: Ipea, 2013. v. 3.

Estupro no Brasil: uma radiografia segundo os dados da saúde (versão preliminar). Ipea: Brasília, 2014. (Nota Técnica, n. 11). Disponível em: <http://repositorio.ipea.gov.br/handle/11058/5780>. Acesso em: 9 set. 2020.

. Redução da idade da imputabilidade penal, educação e criminalidade. Brasília: Ipea, 2015. (Nota Técnica, n. 15). Disponível em: <http://repositorio.ipea.gov.br/handle/11058/5170>. Acesso em: 11 set. 2020. 
. Democracia racial e homicídios de jovens negros na cidade partida. Brasília: Ipea, 2017. (Texto para Discussão, n. 2267). Disponível em: <http://repositorio.ipea.gov.br/handle/11058/7383>. Acesso em: 11 set. 2020.

CERQUEIRA, D.; COELHO, D.; FERREIRA, H. Estupro no Brasil: vítimas, autores, fatores situacionais e evolução das notificações no sistema de saúde entre 2011 e 2014. Rio de Janeiro: Ipea, 2017. (Texto para Discussão, n. 2313). Disponível em: <http://repositorio.ipea.gov.br/ handle/11058/7973>. Acesso em: 7 set. 2020.

CERQUEIRA, D. et al. A singular dinâmica territorial dos homicídios no Brasil nos anos 2000. In: BOUERI, R.; COSTA, M. Brasil em desenvolvimento 2013: estado, planejamento e políticas públicas, Brasília: Ipea, 2013. v. 3.

CERQUEIRA, D. et al. Avaliando a efetividade da Lei Maria da Penha. Brasília: Ipea, 2015. (Texto para Discussão, n. 2048). Disponível em: <http://repositorio.ipea.gov.br/handle/11058/3538>. Acesso em: 11 set. 2020.

CERQUEIRA, D. et al. Atlas da violência 2016. Brasília: Ipea; FBSP, 2016a. (Nota Técnica, n. 17). Disponível em: <http://repositorio.ipea.gov.br/bitstream/11058/6529/1/Nota_n17_Atlas_Violencia. pdf>. Acesso em: 4 set. 2020.

CERQUEIRA, D. et al. Indicadores multidimensionais de educação e homicídios nos territórios focalizados no Pacto Nacional pela Redução de Homicídios. Brasília: Ipea, 2016b. (Nota Técnica, n. 18). Disponível em: <http://repositorio.ipea.gov.br/handle/11058/6518>. Acesso em: 3 set. 2020.

CERQUEIRA, D. et al. Armas de fogo e suicídios. Brasília: Ipea, 2016c. (Texto para Discussão, n. 2254). Disponível em: <http://repositorio.ipea.gov.br/handle/11058/7333>. Acesso em: 11 set. 2020.

CERQUEIRA, D. et al. Atlas da violência 2017. Brasília: Ipea; FBSP, 2017. Disponível em: <http://repositorio.ipea.gov.br/bitstream/11058/7956/1/Atlas\%20da\%20viol\%c3\%aancia_2017. pdf>. Acesso em: 4 set. 2020.

CERQUEIRA, D. et al. Atlas da violência 2018: políticas públicas e retratos dos municípios brasileiros. Brasília: Ipea; FBSP, 2018a. Disponível em: <http://repositorio.ipea.gov.br/bitstream/11058/8698/1/ Atlas\%20da\%20viol\%c3\%aancia\%202018_pol\%c3\%adticas\%20p\%c3\%bablicas\%20e\%20 retratos\%20dos\%20municipios.pdf>. Acesso em: 4 set. 2020.

CERQUEIRA, D. et al. Atlas da violência 2018. Brasília: Ipea; FBSP, 2018b. Disponível em: <http://repositorio.ipea.gov.br/bitstream/11058/8398/1/Atlas\%20da\%20viol\%c3\%aancia_2018. pdf>. Acesso em: 4 set. 2020.

CERQUEIRA, D. et al. Atlas da violência 2019. Brasília: Ipea; FBSP, 2019a. Disponível em: <http://repositorio.ipea.gov.br/bitstream/11058/9406/1/Atlas\%20da\%20viol\%c3\%aancia_2019. pdf>. Acesso em: 4 set. 2020.

CERQUEIRA, D. et al. Atlas da violência 2019: retratos dos municípios brasileiros. Brasília: Ipea; FBSP, 2019b. Disponível em: <http://repositorio.ipea.gov.br/bitstream/11058/9489/1/Atlas_da_ violencia_2019_municipios.pdf>. Acesso em: 4 set. 2020. 
CERQUEIRA, D. et al. Uma análise da base de dados do sistema de informaçóes hospitalar entre 2011 e 2018: dicionário dinâmico, disponibilidade dos dados e aspectos metodológicos para a produção de indicadores sobre violência. Rio de Janeiro: Ipea, 2019c. Disponível em: <http:// repositorio.ipea.gov.br/handle/11058/9409>. Acesso em: 11 set. 2020.

CERQUEIRA, D. et al. Atlas da violência 2020. Brasília: Ipea; FBSP, 2020a. Disponível em: <https:// www.ipea.gov.br/atlasviolencia/download/24/atlas-da-violencia-2020>. Acesso em: 4 set. 2020.

CERQUEIRA, D et al. Atlas da violência 2020 no campo no Brasil: condicionantes e territoriais. Brasília: Ipea; FBSP, 2020b. Disponível em: <https://www.ipea.gov.br/portal/images/stories/PDFs/ relatorio_institucional/200717_relatorio_institucional_atlas_da_violencia.pdf >. Acesso em: 4 set. 2020.

CERQUEIRA, D. et al. Uma avaliação do impacto de política de segurança pública: o programa estado presente do Espírito Santo. Brasília: Ipea, 2020c. (Texto para Discussão, n. 2543). Disponível em: <http://repositorio.ipea.gov.br/bitstream/11058/9704/1/td_2543.pdf>. Acesso em: 4 set. 2020.

CERQUEIRA, D.; FERREIRA, H. Apresentação. In: CERQUEIRA, D.; FERREIRA, H. (Org.). Boletim de Análise Político-Institucional. Brasília: Ipea, n. 11, 2017. Disponível em: <https:/www.ipea.gov.br/ portal/images/stories/PDFs/boletim_analise_politico/171005_bapi_11_1.pdf>. Acesso: 25 ago. 2020.

CERQUEIRA, D.; LIMA, R.; BRAGANÇA, G. Fundo Brasil Paz no Futuro: financiando a eficiência da segurança pública. Brasília: Ipea, 2015. (Texto para Discussão, n. 2077). Disponível em: <http://repositorio.ipea.gov.br/handle/11058/4163>. Acesso em: 11 set. 2020.

CERQUEIRA, D.; MOURA, R. Vidas perdidas e racismo no Brasil. Brasília: Ipea, 2013. (Nota Técnica, n. 10). Disponível em: <http://repositorio.ipea.gov.br/bitstream/11058/5977/1/NT_n10_ vidas.pdf>. Acesso em: 11 set. 2020.

. Custo da juventude perdida no Brasil. In: COURSEUIL, C.; BOTELHO, R. (Org.). Desafios à trajetória profissional dos jovens brasileiros. Rio de Janeiro: Ipea, 2014a. Disponível em: <https://www.ipea.gov.br/portal/images/stories/PDFs/livros/livros/livro_desafios_completoweb.pdf>. Acesso em: 3 set. 2020.

Oportunidades para o jovem no mercado de trabalho e homicídios no Brasil. In: COURSEUIL, C.; BOTELHO, R. (Org.). Desafios à trajetória profissional dos jovens brasileiros. Rio de Janeiro: Ipea, 2014b. Disponível em: <https:/www.ipea.gov.br/portal/images/stories/PDFs/livros/livros/ livro_desafios_completo-web.pdf>. Acesso em: 3 set. 2020.

Oportunidades laborais, educacionais e homicídios no Brasil. Brasília: Ipea, 2019. (Texto para Discussão, n. 2514). Disponível em: <http://repositorio.ipea.gov.br/handle/11058/9427>. Acesso em: 11 set. 2020.

CERQUEIRA, D.; MOURA, R.; PASINATO, W. Participaçáo no mercado de trabalho e violência doméstica contra as mulheres no Brasil. Rio de Janeiro: Ipea, 2019. (Texto para Discussão, n. 2501). Disponível em: <http://repositorio.ipea.gov.br/handle/11058/9358>. Acesso em: 11 set. 2020.

CERQUEIRA, D.; OLIVEIRA JÚNIOR, A.; FERREIRA, H. O desafio da segurança pública. In: MONASTERIO, L.; NERI, M.; SOARES, S. (Ed.). Brasil em desenvolvimento 2014: estado, planejamento e políticas públicas. Brasília: Ipea, 2014. Disponível em: <http://repositorio.ipea.gov. br/handle/11058/3624>. Acesso em: 3 set. 2020. 
CNJ - CONSELHO NACIONAL DE JUSTIÇA. Agenda 2030 no Poder Judiciário: Comitê Interinstitucional. 2 Relatório. Brasília: CNJ, 2020. Disponível em: <https:/www.cnj.jus.br/wpcontent/uploads/2020/04/Segundo-Relatorio-Comite-Interinstitucional-14022020.pdf>. Acesso em: 3 set. 2020.

FERREIRA, H. et al. ODS 16: o que mostra o retrato do Brasil? Brasília: Ipea, 2019. (Série Cadernos ODS). Disponível em: <https:/www.ipea.gov.br/portal/images/stories/PDFs/livros/livros/191114_ cadernos_ODS_objetivo_16.pdf>. Acesso em: 23 out. 2020.

FERREIRA, H.; MARCIAL, E. Violência e segurança pública em 2023: cenários exploratórios e planejamento prospectivo. Brasília: Ipea, 2015. Disponível em: <https://www.ipea.gov.br/portal/ index.php?option=com_content\&view=article\&id=26752>. Acesso em: 17 nov. 2020.

FERREIRA, H.; NATALINO, M.; SANTOS, M. Produção e reprodução das desigualdades pela política criminal. In: PIRES, R. (Org.). Implementando desigualdades: reprodução de desigualdades na implementação de políticas públicas. Rio de Janeiro: Ipea, 2019. Disponível em: <https://www. ipea.gov.br/portal/images/stories/PDFs/livros/livros/190612_implementando_desigualdades.pdf>. Acesso em: 3 set. 2020.

HABER, C., COElHO, D. (Coord.). Planejando a Defensoria Pública do Estado do Rio de Janeiro: uma análise de alocação de defensores entre as comarcas. Rio de Janeiro: Defensoria Pública do Estado do Rio de Janeiro; Ipea, 2017. Disponível em: <http://www.defensoria.rj.def.br/uploads/ arquivos/b05dd02785e44af8b734280d8cff3c9b.pdf>. Acesso em: 23 out. 2020.

IPEA - INSTITUTO DE PESQUISA ECONÔMICA APLICADA. A aplicação de penas e medidas alternativas. Rio de Janeiro: Ipea, 2015a. (Relatório de Pesquisa). Disponível em: <https://www.ipea. gov.br/portal/index.php?option=com_content\&view=article\&id=24862>. Acesso em: 1ํo ago. 2020.

Reincidência criminal no Brasil. Rio de Janeiro, Ipea, 2015b. (Relatório de Pesquisa). Disponível em: <https://www.ipea.gov.br/portal/images/stories/PDFs/relatoriopesquisa/150611_ relatorio_reincidencia_criminal.pdf>. Acesso em: 1aa. 2015.

IPEA - INSTITUTO DE PESQUISA ECONÔMICA APLICADA; CNJ - CONSELHO NACIONAL DE JUSTIÇA. O Poder Judiciário no enfrentamento à violência doméstica e familiar contra as mulheres. Brasília: Ipea; CNJ, 2019. (Relatório). Disponível em: <http:// repositorio.ipea.gov.br/bitstream/1 1058/9530/1/O\%20poder\%20judici\%c3\%a1rio\%20no\%20 enfretamento\%20\%c3\%a0\%20viol\%c3\%aancia\%20dom\%c3\%a9stica\%20e\%20familiar\%20 contra\%20as\%20mulheres.pdf>. Acesso em: 4 set. 2020.

MARQUES, S. et al. Dez anos do projeto Pensando o Direito. Boletim de Análise Político-Institucional. Brasília: Ipea, n. 17, 2018. Disponível em: <https:/www.ipea.gov.br/portal/ images/stories/PDFs/boletim_analise_politico/181206_bapi_17_cap_2.pdf>.Acesso: 3 set. 2020.

MARTINS, A.; CERQUEIRA, D.; MATOS, M. A institucionalizaçáo das políticas públicas de enfrentamento à violência contra as mulheres no Brasil (versáo preliminar). Brasília: Ipea, 2015. (Nota Técnica, n. 13). Disponível em: <http://repositorio.ipea.gov.br/handle/11058/6778>. Acesso em: 11 set. 2020.

MELO, V. Crime organizado: uma concepção introdutória. Brasília: Ipea, 2015. (Texto para Discussão, n. 2121). Disponível em: <http://repositorio.ipea.gov.br/handle/11058/5716>. Acesso em: 11 set. 2020. 
MOURA, T. et al. Mapa da Defensoria Pública no Brasil. Brasília: Ipea; Anadep, 2013. Disponível em: <http://repositorio.ipea.gov.br/handle/11058/2419>. Acesso em: 11 set. 2020.

OLIVEIRA JÚNIOR, A. SIPS segurança pública: confiança e percepção social das polícias. In: SCHIAVIANATTO, F (Org.). Sistema de Indicadores de Percepçáo Social (SIPS). Brasília: Ipea, 2011. Disponível em: <http://repositorio.ipea.gov.br/handle/11058/3097>. Acesso em: 11 set. 2020.

- Importância das atividades de investigação e inteligência policial para o sistema de justiça criminal e seu aprimoramento no Brasil. Boletim de Análise Político-Institucional, Brasília: Ipea, n. 2, 2012. Disponível em: <http://repositorio.ipea.gov.br/bitstream/11058/6765/2/BAPI_n02_p4954_RD_Importancia-atividades_Diest_2012-ago.pdf>. Acesso em: 23 out. 2020.

OLIVEIRA JÚNIOR, A.; ALENCAR, R. SIPS - Sistema de Indicadores de Percepçáo Social: segurança pública. Ipea, 2012. Disponível em: <https://ipea.gov.br/portal/images/stories/PDFs/ SIPS/120705_sips_segurancapublica.pdf>. Acesso em: 3 set. 2020.

OLIVEIRA JÚNIOR, A. et al. Instituiçôes participativas na segurança pública: programas impulsionados por instituições policiais. Boletim de Análise Político-Institucional, Brasília: Ipea, n. 7, 2015. Disponível em: <http://repositorio.ipea.gov.br/handle/11058/6789>. Acesso em: 25 ago. 2020.

OLIVEIRA JÚNIOR, A.; LIMA, V. Segurança pública e racismo institucional. Boletim de Análise Político-Institucional. Brasília: Ipea, n. 4, 2012. Disponível em: <http://repositorio.ipea.gov.br/ handle/11058/5931>. Acesso em: 11 set. 2020.

- Violência letal no Brasil e a vitimização na população negra: qual tem sido o papel das polícias e do Estado? In: SILVA, T.; GOES, F. Igualdade racial no Brasil: reflexôes no ano internacional dos afrodescendentes. Ipea: Rio de Janeiro, 2013. Disponível em: <http://repositorio.ipea.gov.br/ bitstream/11058/9163/1/Violencia_Cap7.pdf>. Acesso em: 11 set. 2020.

OLIVEIRA JÚNIOR, A.; SILVA FILHO, E. Política de segurança pública no Brasil: evolução recente e novos desafios. In: CUNHA, A.; MEDEIROS, B.; AQUINO, L. Estado, instituiçóes e democracia: república. Brasília: Ipea, 2010a. Disponível em: <http://repositorio.ipea.gov.br/ bitstream/11058/3188/1/livro09_Estado_Institui\%C3\%A7\%C3\%B5es_e_Democracia_vol1.pdf>. Acesso em: 1ํago. 2020.

As polícias estaduais brasileiras: o desafio da reforma. In: IPEA - INSTITUTO DE PESQUISA ECONÔMICA APLICADA. Brasil em desenvolvimento: Estado, planejamento e políticas públicas. Brasília: Ipea, 2010b. p. 603-627. Disponível em: <http://repositorio.ipea.gov. br/handle/11058/3804>. Acesso em: 4 set. 2020.

RODRIGUES, R.; AMSTRONG, K. A intervenção federal no Rio de Janeiro e as organizaçóes da sociedade civil: relatório de pesquisa. Rio de Janeiro: Ipea, 2019. Disponível em: <https://www. ipea.gov.br/atlasviolencia/artigo/34/a-intervencao-federal-no-rio-de-janeiro-e-as-organizacoes-dasociedade-civil>. Acesso em: 4 set. 2020.

RODRIGUES, R.; MOTTA, E. A pacificação das favelas do Rio de Janeiro e as organizações da sociedade civil. Boletim de Análise Político-Institucional, Brasília: Ipea, n. 4, 2013. Disponível em: <http://repositorio.ipea.gov.br/handle/11058/5924>. Acesso em: 25 ago. 2020. 
SILVA, E. Agenda 2030: metas nacionais dos Objetivos de Desenvolvimento Sustentável. Brasília: Ipea, 2018. Disponível em: <https:/www.ipea.gov.br/portal/images/stories/PDFs/livros/livros/180801_ ods_metas_nac_dos_obj_de_desenv_susten_propos_de_adequa.pdf>. Acesso em: 26 ago. 2020.

SILVA, F. Desenho, contexto e qualidade deliberativa em conferências nacionais: uma análise dos debates e proposiçóes sobre o Sistema Penitenciário na I Conferência Nacional de Segurança Pública - I CONSEG. In: IPEA - INSTITUTO DE PESQUISA ECONÔMICA APLICADA. Brasil em desenvolvimento: Estado, planejamento e políticas públicas. Brasília: Ipea, 2010. p. 603-627. Disponível em: <http://repositorio.ipea.gov.br/handle/11058/3804>. Acesso em: 4 set. 2020.

. Barcos contra a corrente: a Política Nacional de Segurança Pública de Dilma Rousseff a Michel Temer. Boletim de Análise Político-Institucional. Brasília: Ipea, n. 11, 2017. Disponível em: <http://repositorio.ipea.gov.br/handle/11058/8069>. Acesso em: 25 ago. 2020.

SILVA, F.; DEBONI, F. Participação social e governança democrática na segurança pública: possibilidades para a atuação do Conselho Nacional de Segurança Pública. Brasília: Ipea, 2012. (Texto para Discussão, n. 1714). Disponível em: <http://repositorio.ipea.gov.br/handle/11058/1243>. Acesso em: 25 ago. 2020.

STUCKER, P.; PERRONE, T.; MEDEIROS, C. Pesquisas sobre a aplicação judicial da Lei Maria da Penha: um levantamento bibliométrico e bibliográfico. Rio de Janeiro: Ipea, 2020. (Texto para Discussão, n. 2563). Disponível em: <http://repositorio.ipea.gov.br/handle/11058/10052>. Acesso em: 11 set. 2020.

TRABALHOS ANTERIORES À CRIAÇÃO DA DIEST E TRABALHOS POSTERIORES PRODUZIDOS ATÉ 2012 EM OUTRAS DIRETORIAS POR PESQUISADORES QUE PASSARAM A INTEGRAR A DIEST

CERQUEIRA, D. Fórum de debates - criminalidade, violência e segurança pública no Brasil: uma discussão sobre a base de dados e questôes metodológicas. In: CERQUEIRA, D.; LEMGRUBER, J.; MUSUMECI, L. (Org.). Fórum de debates - criminalidade, violência e segurança pública no Brasil: uma discussão sobre a base de dados e questóes metodológicas. Rio de Janeiro: Ipea, CESeC, 2000.

. Segurança Pública. Políticas sociais: acompanhamento e análise. Brasília: Ipea, n. 5, 2002. Disponível em: <https://www.ipea.gov.br/portal/images/stories/PDFs/politicas_sociais/bps_05.pdf>. Acesso em: 1ำago. 2020.

Segurança Pública. Políticas sociais: acompanhamento e análise. Brasília: Ipea, n. 6, 2003a. Disponível em: <https:/www.ipea.gov.br/portal/images/stories/PDFs/politicas_sociais/ SEGURANcA_PuBLICA6.pdf>. Acesso em: 1ำago. 2020.

. Segurança Pública. Políticas sociais: acompanhamento e análise. Brasília: Ipea, n. 7, 2003b. Disponível em: <https:/www.ipea.gov.br/portal/images/stories/PDFs/politicas_sociais/ SEGURANCA_PUBLICA7.pdf>. Acesso em: 1ำ ago. 2020. 
. Direitos Humanos, Justiça e Cidadania. Políticas sociais: acompanhamento e análise. Brasília: Ipea, n. 8, 2004a. Disponível em: <https:/www.ipea.gov.br/portal/images/stories/PDFs/ politicas_sociais/DIREITOS_HUMANOS8.pdf>. Acesso em: 1ำ ago. 2020.

. Direitos Humanos, Justiça e Cidadania. Políticas sociais: acompanhamento e análise. Brasília: Ipea, n. 9, 2004b. Disponível em: <https:/www.ipea.gov.br/portal/images/stories/PDFs/ politicas_sociais/DIREITOS_HUMANOS9.pdf>. Acesso em: 1a ago. 2020.

. Direitos Humanos, Justiça e Cidadania. Políticas sociais: acompanhamento e análise. Brasília: Ipea, n. 10, 2005. Disponível em: <https://www.ipea.gov.br/portal/images/stories/PDFs/ politicas_sociais/DIREITOS_HUMANOS10.pdf>. Acesso em: 1ํago. 2020.

. Direitos Humanos, Justiça e Cidadania. Políticas sociais: acompanhamento e análise. Brasília: Ipea, n. 13, 2007. (Edição Especial). Disponível em: <https:/www.ipea.gov.br/portal/ images/stories/PDFs/politicas_sociais/Direitos_Humanos_Justica_Cidadania13.pdf $>$. Acesso em: $1 \stackrel{0}{ }$ ago. 2020 .

- Justiça e Segurança Pública. Políticas sociais: acompanhamento e análise. Brasília: Ipea, n. 15, 2008a. Disponível em: <https://www.ipea.gov.br/portal/images/stories/PDFs/politicas_ sociais/13_justicatabelafinal15.pdf>. Acesso em: 1ํo ago. 2020.

- Justiça e Segurança Pública. Políticas sociais: acompanhamento e análise. Brasília: Ipea, n. 16, 2008b. Disponível em: <https:/www.ipea.gov.br/portal/images/stories/PDFs/politicas_ sociais/13_justicatabelafinal15.pdf>. Acesso em: 1a ago. 2020.

IPEA - INSTITUTO DE PESQUISA ECONÔMICA APLICADA. Políticas sociais: acompanhamento e análise. Brasília: Ipea, n. 3, 2001. Disponível em: <http://repositorio.ipea.gov. br/bitstream/11058/4174/1/bps_03_completo.pdf>. Acesso em: 1ํo ago. 2020.

. Políticas sociais: acompanhamento e análise. Brasília: Ipea, n. 4, 2002. Disponível em: <https://www.ipea.gov.br/portal/images/stories/PDFs/politicas_sociais/bps_04.pdf>. Acesso em: 1ำ ago. 2020 .

RODRIGUES, R. Diagnóstico e desempenho recente do Programa Nacional de Segurança Pública com Cidadania. In: IPEA - INSTITUTO DE PESQUISA ECONÔMICA APLICADA. Brasil em desenvolvimento: Estado, planejamento e políticas públicas. Brasília: Ipea, 2009. v. 3. Disponível em: <https://www.ipea.gov.br/bd/pdf/2009/Livro_BrasilDesenvEN_Vol03.pdf>. Acesso em: 1ํo ago. 2009.

\section{ESTES DOIS LEVANTAMENTOS ARROLAM OUTROS TRABALHOS AQUI NÃO MENCIONADOS}

IPEA - INSTITUTO DE PESQUISA ECONÔMICA APLICADA. Texto para Discussão. Brasília: Ipea, n. 1000, 2004. (Edição Especial). Disponível em: <https://www.ipea.gov.br/portal/images/ stories/PDFs/TDs/td_1000.pdf>. Acesso em: 31 jul. 2020.

LIMA, J. C.; DIAS, R. (Org.). Pesquisas e propostas. Brasília: Ipea, 2014. (Texto para Discussão, n. 2000). 


\section{TRABALHOS QUE PERPASSAM OS TEMAS DE SEGURANÇA PÚBLICA E VIOLÊNCIA E ANTERIORES AO INÍCIO DA PRODUÇÃO PRÓPRIA DO IPEA FOCADA NESSES TEMAS}

BARROS, M. E.; PIOLA, S. F.; VIANNA, S. M. Política de saúde no Brasil: diagnóstico e perspectivas. Brasília: Ipea, 1996. (Texto para Discussão, n. 401). Disponível em: <http://repositorio. ipea.gov.br/handle/11058/1835>. Acesso em: 1ํo ago. 2020.

DEMO, P.; OLIVEIRA, L. Cidadania e direitos humanos - sob o olhar das políticas públicas. Brasília: Ipea, 1995. (Texto para Discussão, n. 391). Disponível em: <http://repositorio.ipea.gov. br/handle/11058/1819>. Acesso em: 1ํago. 2020.

IPEA - INSTITUTO DE PESQUISA ECONÔMICA APLICADA; UNICEF - FUNDO DAS NAÇÓES UNIDAS PARA A INFÂNCIA. A criança no Brasil: o que fazer? Brasília: Ipea/Iplan, 1990. Disponível em: <http://repositorio.ipea.gov.br/handle/11058/9041>. Acesso em: 1a ago. 2020.

MUSUMECI, L. Serviços privados de vigilância e guarda no Brasil: um estudo a partir de informações da Pnad - 1985-1995. Rio de Janeiro: Ipea, 1998. (Texto para Discussão, n. 560). Disponível em: <http://repositorio.ipea.gov.br/bitstream/11058/2401/1/TD\%200560.pdf>. Acesso em: $1^{\circ}$ ago. 2020.

PIANCASTELLI, M.; PEREIRA, F. Gasto público federal: análise da despesa não financeira. Brasília: Ipea, 1996. (Texto para Discussão, n. 431). Disponível em: <http://repositorio.ipea.gov. br/bitstream/11058/1947/1/td_0431.pdf>. Acesso em: 1ํo ago. 2020.

SILVA, F. A evolução das funções do governo e a expansão do setor público brasileiro. Pesquisa e Planejamento. Rio de Janeiro: Ipea, v. 1, n. 2, p. 235-282, dez. 1971.

SOBRINHO, J.; PARENTE, M. CAIC: solução ou problema? Brasília: Ipea, jan. 1995. (Texto para Discussão, n. 363). Disponível em: <http://repositorio.ipea.gov.br/bitstream/11058/1717/1/ td_0363.pdf>. Acesso em: 1ำago. 2020. 